В. Н. Чисников, доктор юридических наук, доцент,

главный научный сотрудник

отдела научно-информачионной

и редакиионно-издательской деятельности,

Государственный научно-исследовательский институт

МВД Украинь, г. Киев

ORCID: https://orcid.org/0000-0003-2020-7298

\title{
ЕЛИСЕЕВ АЛЕКСАНДР АКИМОВИЧ - ОДИН ИЗ ПЕРВЫХ РУКОВОДИТЕЛЕЙ НАУЧНО-ТЕХНИЧЕСКОЙ ЧАСТИ ОТДЕЛА УГОЛОВНОГО РОЗЫСКА ГЛАВНОГО УПРАВЛЕНИЯ МИЛИЦИИ И РОЗЫСКА УССР
}

\begin{abstract}
На основе малоизвестных украинских милицейских изданий 20-х годов XX в., а также опубликованных работ по истории криминалистики рассматривается жизненный путь и творческая деятельность Александра Акимовича Елисеева (1887-1968) - одного из пионеров советской криминалистики, внесшего значительный вклад в развитие криминалистической науки и судебной экспертизы в Украине. Обращается внимание преимущественно на деятельность А. А. Елисеева в период его пребывания руководителем научнотехнической части (подотдела) отдела уголовного розыска Главного управления милиции и розыска УССР (1923-1926). Разработанные им в эти годы различные ведомственные руководства, инструкции, методические указания, а также опубликованные статьи сыграли важную роль в распространении криминалистических знаний среди практических работников Украины.

Ключевые слова: Елисеев А. А., научно-техническая часть (подотдел) Укрцентророзыска; регистрационно-дактилоскопическое бюро; Харьковский кабинет научно-судебной экспертизы НКЮ УССР; проблемы почерковедения; судебно-графическая экспертиза; история криминалистики.
\end{abstract}



В криминалистической литературе имя А. А. Елисеева хорошо известно. С его краткой биографией можно ознакомиться во многих юридических и криминалистических изданиях. Среди них следует выделить работу В. С. Печникова, в которой, в отличие от других исследований, биография Александра Акимовича излагается более расширенно.

Автор данной публикации (Piechnikov, 2011, s. 83-84) ставит своей целью, используя, главным образом, материалы периодики НКВД УССР 20-х гг. прошлого столетия, осветить деятельность А. А. Елисеева на посту начальника научно-технической части (подотдела) Укрцентророзыска (1923-1926), вкратце характеризуя его работы в этот период времени.

Александр Акимович Елисеев родился 10 августа 1887 г. в Твери (Россия), в крестьянской семье. Вскоре семья переехала в Полоцк (Польша), где отец Александра служил контролером. Среднее образование юноша получил в полоцкой гимназии (1896-1905). Будучи гимназистом, принимал участие в кружке российской социал-демократической рабочей партии (РСДРП), распространял нелегальную литературу, агитировал против царского самодержавия. В 1905-1907 гг. подвергался обыску и аресту. Скрываясь от полиции, перебрался в Петербург, где поступил на Высшие курсы Побединского, і два года изучал экономику. По окончании учебы (1909) получил квалификацию экономиста-бухгалтера.

В течение 1910-1918 гг. А. А. Елисеев трудился помощником секретаря Полоцкого окружного суда, кладовщиком на Варшавской таможне, а после переезда в Тверь снова занял должность секретаря окружного суда. В годы гражданской войны Александр Акимович заведовал финансовым отделом Тверского губернского отдела юстиции, а также руководил губернским отделом профсоюза советских работников торговли. В 1920-1921 гг. ему пришлось служить в рядах Красной армии, в политотделе Юго-Западного



(C) В. Н. Чисников, 2021 
фронта. После демобилизации бывший политрук Елисеев непродолжительное время работал старшим инспектором Украинского таможенного округа в г. Харькове. В начале 1923 г. оставил занимаемую должность и лишился партийного билета члена ВКП(б) «из-за склоки, имевшей место в Украинском таможенном округе» (Piechnikov, 2011, s. 83-84).

Однако вышеуказанные обстоятельства не помешали А. А. Елисееву в том же году устроиться на работу в Главное управление милиции и розыска УССР, которое остро нуждалось в специалистах, и занять должность начальника научно-технического подотдела Укрцентророзыска.

Говоря о пребывании Александра Акимовича на этом посту, необходимо уточнить некоторые детали. Во-первых, практически во всех его биографиях, с подачи профессора Р. С. Белкина, указывается, что А. А. Елисеев - «первый начальник научно-технического отделения Главного управления милиции и розыска Украины» (курсив наш. B. Ч.) (Belkin (Avt.-sost.), 1993, s. 26).

Между тем данное утверждение уважаемого профессора не соответствует действительности. Как ранее было установлено автором настоящей статьи, первым руководителем указанного подразделения был профессор Александр Дмитриевич Киселев (1867-1926), занявший эту должность 15 июня 1921 г. (Chysnikov, 2011, s. 198).

Во-вторых, украинские биографы криминалиста, ссылаясь на книгу Р. С. Белкина и А. И. Винберга, утверждают, что с 1924 г. Александр Акимович уже работал заведующим секцией идентификации Харьковского кабинета научно-судебной экспертизы, т. е. в предыдущей должности он состоял не более года (Bilenchuk, \& Starushkevych, 1990, s. 416). Заметим, что в цитированной книге указывается, что А. А. Елисеев в 1924 г. «начинаem сотрудничать с Харьковским кабинетом научно-судебной экспертизы» (курсив наш. - В. Ч.) (Belkin, \& Vinberg, 1982, s. 39).

Автор книги «Є така служба...» В. С. Печников в подтверждение этого факта разместил фото, датированное 1924 г., на котором А. А. Елисеев запечатлен среди сотрудников Харьковского кабинета научно-судебной экспертизы (Piechnikov, 2011, s. 84).

Нам представляется, что Александр Акимович должность начальника научно-технического подотдела Укрцентророзыска занимал на протяжении трех лет, работая по совместительству в Харьковском кабинете научно-судебной экспертизы. Об этом свидетельствует подпись «Начальник научно-технической части угрозыска УССР» под его статьей «Преступность и борьба с ней в УССР», опубликованной в журнале «На посту» (Ленинград) (Eliseev, 1926a, s. 560).



Зліва направо: П. М. Вроблевський,

М. С. Бокаріус, О. Я. Єлисєєв, П. К. Вируб, 1924 р.

А теперь более подробно рассмотрим труды А. А. Елисеева в период пребывания его на вышеуказанной должности. Первая известная его научная статья появилась в декабре 1923 г. в журнале милиции и розыска республики «Щит революционного порядка» в рубрике «Уголовный ро-

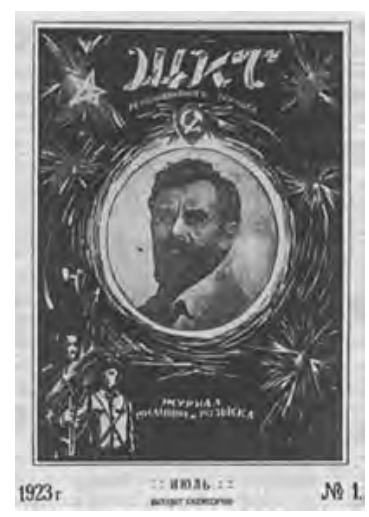
зыск» под названием «Преступность и организация борьбы с ней».

В начале статьи автор, ссылаясь на показатели уголовной статистики, констатировал, что «ныне мы стоим перед фактом значительного увеличения преступности», которая «растет с каждым годом и в сравнении с довоенной выросла почти в 8 раз». При этом он, в качестве примера, приводил такой факт: в 1922 г. только в учреждениях уголовного розыска УССР, в девяти губерниях Украины, по недостаточно полным сведениям было зарегистрировано 145859 преступлений.

Рост преступности в стране, по словам А. А. Елисеева, объясняется рядом социальноэкономических причин, среди которых: освобождение из тюрем Временным правительством неисправимого уголовного элемента, а также «голод, холод, экономическая разруха и безработица, которая толкнула менее устойчивых лиц на всякого рода преступные комбинации».

Говоря о преступности в условиях новой экономической политики, автор отмечал, что она «изменяет свои формы и проявления», а преступник «стал применять различные способы, достигнутые наукой (физикой, химией и т. п.) и усовершенствованные орудия преступления, в интересах «своего» злодейского дела». Применяя эти разнообразные способы, он, прежде всего, стремится не оставить за собой следов и улик и, таким образом, избежать наказания за совершенное преступление. 
Поэтому, по утверждению А. А. Елисеева, сотрудникам уголовного розыска и наружной милиции, ведущим борьбу с уголовной преступностью, необходимо «противопоставить, кроме применяемых выслеживаний, научные методы борьбы».

Переходя к освещению методов работы, используемых в розыскном деле, Александр Акимович подчеркивал, что «ныне раскрытие преступлений перестает быть каким-то ремеслом, сводящим к одному выбиванию от обвиняемого сознания. Оно становится уже искусством, для которого требуются научные данные. Применяемая в розыске секретно-агентурная работа должна быть предварительно умело и тщательно проверена».

Для успешной борьбы с преступностью, по А. А. Елисееву, уголовный розыск должен: во-первых, применяя усовершенствованные средства, вести самую точную регистрацию преступников по способу дактилоскопии, фотографирования и словесного портрета; во-вторых, вести систематический учет притонов и сборищ преступников, проживающих в данном месте лиц, условно осужденных, промышляющих сводничеством, сутенерством, осужденных за преступления и т. д.; в-третьих, вести секретно-агентурную работу для предупреждения и раскрытия преступлений; в-четвертых, опознавать присылаемых преступников и, в-пятых, быть специалистом по раскрытию уже совершенных преступлений, применяя собак-ищеек.

По твердому убеждению автора, наиболее существенной формой борьбы с преступностью является регистрация преступников, к методам которой относятся: дактилоскопия, фотография и словесный портрет и как подсобный вспомогательный способ - издание справочников о судимости.

Из всех вышеуказанных способов, А. А. Елисеев выделял дактилоскопию, которая «является наиболее точной и простой». При этом он отмечал: «Единственное, что требуется для этого, - кадры специально подготовленных, хорошо развитых и грамотных работников, т. к. иначе положительные результаты достигнуты не будут».

Далее для успешного выполнения работы по борьбе с преступностью Александр Акимович предлагал при каждом уголовный розыске, а там, где его нет, - при милиции организовать Регистрационно-дактилоскопические бюро. Их главные задачи должны состоять в том, чтобы:

по имени и фамилии преступника найти его фотографию и описание наружности;

по доставленным отпечаткам пальцев или фотографии преступника установить его личность; по описанию наружности преступника лицом, видевшим его, определить личность преступника;

по обнаруженным на месте происшествия следам от прикосновения к чему-либо определить его личность;

дать полные сведения о преступном прошлом преступника.

В заключении статьи Александр Акимович делал взвод: в нынешних условиях сокращения аппаратов уголовного розыска необходимо подходить «очень осторожно». Не увлекаясь сокращением кадров, нужно «укреплять его ряды как квалифицированными работниками, так и необходимыми средствами, и нужным техническим оборудованием для применения научных методов работы... Розыск, построенный на научных методах работы - является могучим средством борьбы с преступностью» (Eliseev, 1923, s. 12-13).

Наступающий 1924 г. был для А. А. Елисеева особенно продуктивным в плане разработки и издания ведомственных нормативных актов и совместного сотрудничества с консультантом уголовного розыска республики профессором Н. С. Бокариусом.

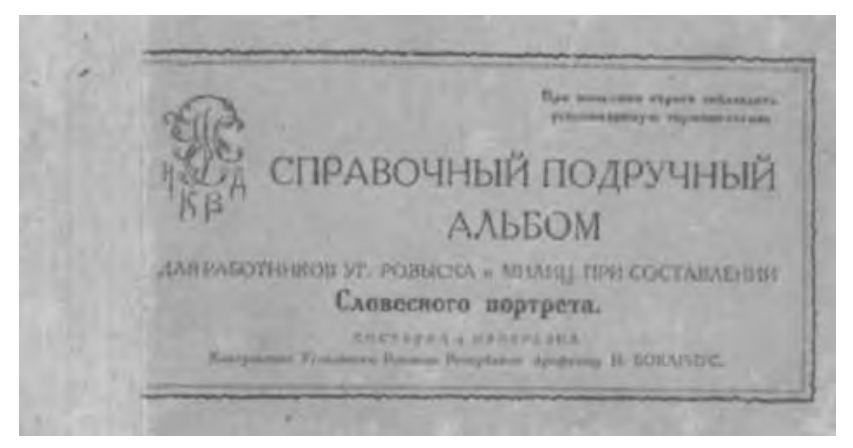

В начале года Управление милиции и уголовного розыска УССР выпустило «Справочный подручный альбом для работников уголовного розыска и милиции при составлении словесного портрета», разработанного Н. С. Бокариусом (Bokarius (Sost.), 1924). В предисловии к альбому начальник научно-технического подотдела Укрцентророзыска А. А. Елисеев писал: «Издание настоящего альбомчика по «словесному портрету» вызвано настоятельной необходимостью дать по возможности практическое, наглядное пособие, не только при описании личности регистрируемого преступника в Регистрационно-Дактилоскопическом Бюро, но и подручный справочник для работников Уголовного розыска и Милиции при розыске преступника...

Применение описания наружности человека в наших Уголовно-розыскных органах может оказать незаменимые услуги по розыску лиц, в особенности окружных городах, где Регистрационные Бюро при Уголовных Розысках пока не 
везде имеют фотографическую регистрацию» (Piechnikov, 2011, s. 86).

В августе того же года Управление милиции и уголовного розыска республики издало «Руководство регистрационно-дактилоскопическим бюро милиции и уголовного розыска УССР» (104с.), авторами которого были начальник научно-технического подотдела Укрцентророзыска А. А. Елисеев и консультант уголовного розыска республики профессор Н. С. Бокариус.



Руководство включало: Инструкцию регистрационно-дактилоскопическим бюро при учреждениях уголовного розыска (сост. А. А. Елисеев); Правила по дактилоскопированию и фотографированию регистрируемых преступников (сост. А. А. Елисеев и Н. С. Бокариус); Приложение: образцы журналов и книг учета, дактилоскопического «листка», протоколов опознания, справок по результатам проверки, формы отчетности и т. д., а также приказы и циркуляры НКВД и НКЮ по вопросам координации и разделения функций.

Издание имело большое практическое значение, охватывая наиболее существенные и главные моменты регистрации, отождествления, розыска и классификации преступного элемента.

Например, Правила по дактилоскопированию и фотографированию регистрируемых преступников состояли из 9 разделов: І. Дактилоскопия как метод регистрации; II. О приемах дактилоскопирования... VIII. Фотография в Уголовном розыске (Сигналитическая фотография). Фотографирование преступников для регистрационных карточек; IX. Таблица распределения преступников по виду преступлений.

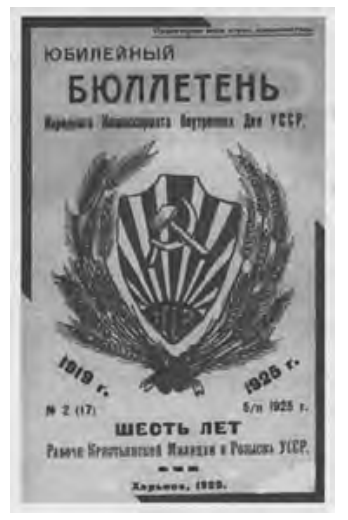

В Юбилейном Бюллетене НКВД УССР (1925) рецензент Е. Майоров отмечал: «Одним из главных достоинств «Руководства» является та характерная его особенность, что оно сумело в малом объеме сконцентрировать и сосредоточить большое и разнообразное количество различных связанных между собою сведений и материалов по регистрации, отождествлению, розыску и классификации преступников, отчего можно с уверенностью сказать, что отдел милиции и розыска УССР, составив и издав «Руководство», сделал ценный вклад в криминальную литературу» (Maiorov, 1925, s. 74).

В этом же номере журнала была помещена статья А. А. Елисеева «Регистрация преступников и ее значение в уголовном розыске». Автор, характеризуя состояние организации регистрации преступного элемента в органах уголовного розыска УССР, отмечал, что в Центральном дактилоскопическом бюро имеется 21800 регистрационных карточек, благодаря которым только в 1924 г. «удалось по отпечаткам пальцев установить правильную фамилию у 383 лиц, проходивших под разными фамилиями и зарегистрированных в разных местах республики, о которых своевременно дано знать местам».

При этом Александр Акимович подчеркивал, что существующая ныне в республике регистрация преступников сводится главным образом к дактилоскопированию и фотографированию, которые дают возможность только установить личность преступника и «почти не дают сведений о его нравственности, условиях быта, об особенностях его преступной деятельности и вообще обрисовки личности, между тем, как эти сведения для изучения преступности имеют важное значение».

В связи с этим автор статьи сообщал читателям, что руководство милиции и розыска республики через научно-техническое отделение поставило своей очередной задачей «разработку и проведение в жизнь по всем регистрационным бюро постановки дополнительной регистрации по способам: 1) словесного портрета; 2) по роду преступлений и методам совершения преступлений; 3) по татуировкам и уродливости (т. е. по физическим недостаткам и приметам); 4) по кличкам и прозвищам преступников, принятых в преступном мире».

Вкратце охарактеризовав указанные способы регистрации, А. А. Елисеев заключал: «Приведенные способы подсобной регистрации, в общей совокупности, дают возможность изучить моральную и физическую сторону преступника, которые нам крайне необходимы, не говоря о том, что они будут служить большим подспорьем в деле розыска лиц» (Eliseev, 1925, s. 54-57).

В 1926 г. в Харькове Государственное издательство Украины выпустило книгу «Красный страж» - сборник статей, материалов и рассказов о жизни и деятельности милиции и розыска УССР под редакцией и с предисловием наркома юстиции республики Н. А. Скрыпника.




В предисловии нарком, в частности, отмечал, что цель настоящей книги - «дать краткий, охватывающий вопросы жизни и работы милиции, очерк ее задач, ее положения в общей системе наших государственных органов... дать не панегирик милиции, а возможно полный очерк ее задач и ее истории, ее достижений и успехов, ее поражений и потерь» (Skrypnik, 1926, s. III, УII).

Книга состояла из трех разделов: I. О милиции; II. Путь милиции; III. Рассказы из жизни милиции. Во втором разделе после статьи начальника милиции и розыска УССР И. Якимовича была помещена статья А. Елисеева (должность не указана) «Регистрация как метод розыска». Она размещалась на шести страницах и была иллюстрирована тремя фотоснимками: дактилоскопирование преступника; дактилоскопирование трупа после вскрытия; фотографирование преступника.

По своему содержанию работа представляла переделанный вариант статьи А. А. Елисеева, опубликованной в Юбилейном Бюллетене НКВД УССР (1925). Заканчивал ее автор оптимистически: «Научные методы сыска все больше и больше входят в практику розыскного аппарата республики, и это дает основание полагать, что чем дальше, тем больше и лучше органы розыска будут выполнять возложенные на них задачи» (Eliseev, 1926b, s. 46-51).



В этом же году в журнале «Адміністративний Вісник» (№ 4/5) появилась рецензия А. А. Елисеева на книгу немецкого криминалиста доктора Ганса Шнейкерта «Введение в уголовную технику», изданную на русском языке в Москве.

Александр Акимович, в частности, писал, что «перевод этой книги на русский язык восполняет пробел в нашей литературе по вопросам разного вида регистрации преступного элемента, который всячески стремится избежать опознания его работниками милиции и уголовного розыска как путем изменения наружности, так и перемены своей фамилии».

Далее рецензент, характеризуя содержание книги, отмечал, что она состоит из трех частей (учение об описании примет; о службе опознания и ее вспомогательных средствах; способы сохранения следов и вещественных доказательств совершения преступлений), а также Приложения, в котором «даются весьма полезные сведения о психологическом испытании лиц в способностях к уголовно-розыскной службе».

По мнению А. А. Елисеева, «книга принесет несомненную пользу работникам уголовного ро- зыска и милиции, которые при внимательном прочтении могут ознакомиться с существующими научными способами регистрации преступников, а также собиранием и систематизацией материалов, способствующих раскрытию преступлений» (Eliseev, 1926c, s. 49).

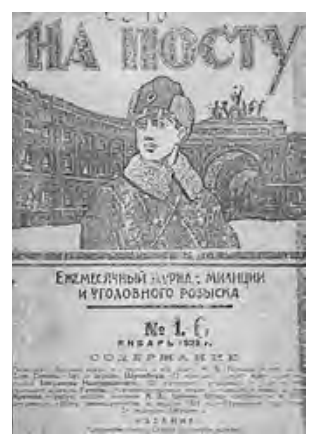

Одной из последних работ Александра Акимовича в период пребывания его в должности начальника научно-технического подотдела Укрцентророзыска была статья «Преступность и борьба с ней в УССР», опубликованная в журнале «На посту» (Ленинград) 1926 (№ 14), который был полностью посвящен вопросам организации и работы админорганов, милиции и угрозыска УССР.

Характеризуя положительную динамику борьбы с преступностью в Украине, А. А. Елисеев в то же время отмечал, что «преступный элемент за последнее время, в свою очередь, пользуется достижениями науки и техники, и потому необходимо обратить внимание общественных сил на борьбу с разрастающейся преступностью, для чего органы, ведущие борьбу с ней, должны быть снабжены необходимыми средствами и техническим оборудованием для широкого применения научных методов работы. Потраченные на это средства с избытками возместятся и воспрепятствуют росту преступности» (Eliseev, 1926а, s. 557-560).

Работая в Харьковском кабинете научно-технической экспертизы НКЮ УССР, Александр Акимович возглавлял секцию идентификации. Под его руководством разрабатывались, в частности, проблемы почерковедения, а также вопросы практического научно-криминалистического обеспечения раскрытия и расследования преступлений. В этот период были опубликованы его работы: «Преступление и экспертиза почерка», «Закрепление следов гипсом», «Збирання і закріплення різних слідів при розслідуванні злочинів» (все 1928 г.).

В 1929 г. А. А. Елисеев перешел на преподавательскую работу, где в течение пяти лет читал курс криминалистики, заведуя «уголовно-розыскным обучением» в 3-й Новочеркасской школе старшего начальствующего состава административно-милицейских работников. После сокращения курса криминалистики возвратился в Харьковский научно-исследовательский институт судебных экспертиз, где снова возглавил отдел идентификации, являясь старшим научным сотрудником. С 1 февраля 1941 г. по совместительству исполнял 
должность помощника директора института, а с началом войны эвакуирован в глубь страны, где работал прокурором следственного отдела в Чкаловской и Пензенской областях.

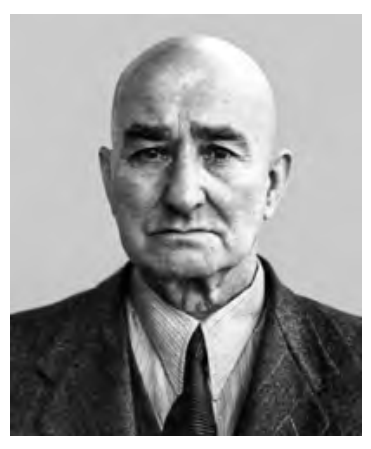

В 1944 г., после освобождения Украины от немецко-фашистских захватчиков, Александр Акимович снова возвратился в Харьковский научно-исследовательский институт судебных экспертиз им. Н. С. Бокариуса, заняв прежнюю свою должность заведующего отделом идентификации. Параллельно преподавал криминалистику в Харьковском юридическом институте и Харьковской юридической школе. После ухода на пенсию (1964) не порывал связей с ХНИИСЭ. Умер 7 декабря 1968 г.

Как утверждают биографы А. А. Елисеева, его перу принадлежит около 40 научных работ, среди которых научно-методические руководства, инструкции, рекомендации, научные статьи по актуальным вопросам криминалистики и судебной экспертизы. Среди основных его публикаций довоенного и послевоенного периода следует назвать: «Осмотр мест преступлений» (1936); «Пыль и грязь как доказательства» (1937);

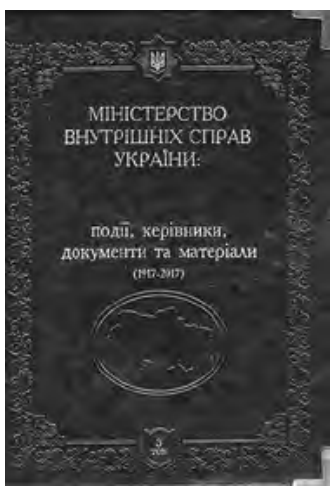
«Методическое письмо о судебно-графической экспертизе» (1947); «Криминалистическая экспертиза подписей» (1948); «Установление личности по искаженному почерку» (1959); «Фрагменти історії розвитку радянської криміналістики в УРСР» (1964) и др.

В заключение отметим, что некоторые работы А. А. Елисеева были включены автором данной статьи в третий том книги «Міністерство внутрішніх справ України: події, керівники, документи та матеріали (1917-2017)» (Verbenskyi et al., 2015, s. 196-199, 302-306, 374-382, 399-401, 532-533).

\section{References}

Belkin, R. S., \& Vinberg, A. I. (1982). Istoriia sovetskoi kriminalistiki. Etap vozniknoveniia i stanovleniia nauki (1917-1930-e gody): ucheb. posobie. M.: NI i RIO. 70 c. [in Russian].

Belkin, R. S. (Avt.-sost.). (1993). Kriminalistika. Kratkaia entciklopediia. M.: Nauch. izd. BRE. 111 s. [in Russian].

Bilenchuk, P. D., \& Starushkevych, A. V. (1998). Yelysieiev Oleksandr Yakymovych. V Shemshuchenko, Yu. S. (Red.). Yurydychna entsyklopediia. (T. 2: D - Y, s. 416). Kyiv: Ukr. entsykl [in Ukrainian].

Bokarius, N. (Sost.). (1924). Spravochnyi podruchnyi albom dlia rabotnikov ugolovnogo rozyska $i$ militcii pri sostavlenii slovesnogo portreta. Kharkov: Upravlenie militcii i ugolovnogo rozyska respubliki. $87 \mathrm{~s}$. [in Russian].

Chysnikov, V. M. (2011). Vchenyi-kryminalist profesor O. D. Kisilov: nevidomi storinky biohrafii. Kryminalistychnyi visnyk, 1 (15), 195-207 [in Ukrainian].

Eliseev, A. (1923). Prestupnost i organizatciia borby s nei. Shchit revoliutcionnogo poriadka, 5-6, 12-13 [in Russian].

Eliseev, A. (1925). Registratciia prestupnikov i ee znachenie v ugolovnom rozyske. Iubileinyi Biulleten Narodnogo Komissariata Vnutrennikh Del USSR, 2 (17), 54-57 [in Russian].

Eliseev, A. (1926a). Prestupnost i borba s nei v USSR. Na postu, 14, 557-560 Leningrad. [in Russian].

Eliseev, A. (1926b). Registratciia kak metod rozyska. Krasnyi strazh. Kharkov: Gos. izd-vo Ukrainy. 227 s. [in Russian].

Eliseev, A. (1926c). Retcenziia na knigu: Shneikert Gans. Doktor prava. Vvedenie v ugolovnuiu tekhniku. Rukovodstvo dlia shkol i kursov po podgotovke rabotnikov militcii i ugolovnogo rozyska. Per. s nem. M.: Gosudarstvennoe Tekhnicheskoe izdatelstvo. 184 s. Administrativnii Visnik, 4/5, 49 [in Russian].

Maiorov, E. (1925). Rukovodstvo registratcionno-daktiloskopicheskim biuro militcii i ugolovnogo rozyska USSR. Iubileinyi Biulleten Narodnogo Komissariata Vnutrennikh Del USSR, 2 (17), 74 [in Russian].

Piechnikov, V. S. (2011). Ye taka sluzhba... (I. P. Krasiuk, Red.). Kyiv: Elit Print. T. 1. Ch. 1. 585 s. [in Ukrainian].

Skrypnik, N. (1926). Predislovie. Krasnyi strazh. Kharkov: Gos. izd-vo Ukrainy. 277 s. [in Russian].

Verbenskyi, M. H., Yarmysh, O. N., Protsenko, T. O., Kryvolapchuk, V. O., Chysnikov, V. M., Pluhatar, T. A., Dovbnia, V. A., \& Kozhukhar, O. V. (2015). V A. B. Avakov (Red.), Ministerstvo vnutrishnikh sprav Ukrainy: podii, kerivnyky, dokumenty ta materialy (1917-2017) (T. 3, 940 s.). Kharkiv: Machulin [in Ukrainian].

\section{Список использованных источников}

Белкин, Р. С., \& Винберг, А. И. (1982). История советской криминалистики. Этап возникновения и становления науки (1917-1930-е годы): учеб. пособие. М.: НИ и РИО. 70 с.

Белкин, Р. С. (Авт.-сост.). (1993). Криминалистика. Краткая энииклопедия. М.: Науч. изд. БРЭ. 111 с.

Біленчук, П. Д., \& Старушкевич, А. В. (1999). Єлисєєв Олександр Якимович. В Шемшученко, Ю. С. (Ред.). Юридична енциклопедія. (Т. 2: Д - Й, с. 416). Київ: Укр. енцикл.

Бокариус, Н. (Сост.). (1924). Справочный подручный альбом для работников уголовного розыска и милиции при составлении словесного портрета. Харьков: Управление милиции и уголовного розыска республики. 87 с. 
Чисніков, В. М. (2011). Вчений-криміналіст професор О. Д. Кісільов: невідомі сторінки біографії. Криміналістичний вісник, 1 (15), 195-207.

Елисеев, А. (1923). Преступность и организация борьбы с ней. Щит революционного порядка, 5-6, 12-13.

Елисеев, А. (1925). Регистрация преступников и ее значение в уголовном розыске. Юбилейный Бюллетень Народного Комиссариата Внутренних Дел УССР, 2 (17), 54-57.

Елисеев, А. (1926а). Преступность и борьба с ней в УССР. На посту, 14, 557-560. Ленинград.

Елисеев, А. (1926b). Регистрация как метод розыска. Красный страж. Харьков: Гос. изд-во Украины. 227 с.

Елисеев, А. (1926c). Рецензия на книгу: Шнейкерт Ганс. Доктор права. Введение в уголовную технику. Руководство для школ и курсов по подготовке работников милиции и уголовного розыска. Пер. с нем. М.: Государственное Техническое издательство. 184 с. Адміністративний Вісник, 4/5, 49.

Майоров, Е. (1925). Руководство регистрационно-дактилоскопическим бюро милиции и уголовного розыска УССР. Юбилейный Бюллетень Народного Комиссариата Внутренних Дел УССР, 2 (17), 74.

Пєчніков, В. С. (2011). Є така служба... (І. П. Красюк, Ред.). Київ: Еліт Прінт. Т. 1. Ч. 1.585 с.

Скрыпник, Н. (1926). Предисловие. Красный страж. Харьков: Гос. изд-во Украины. 277 с.

Вербенський, М. Г., Ярмиш, О. Н., Проценко, Т. О., Криволапчук, В. О., Чисніков, В. М., Плугатар, Т. А., Довбня, В. А., \& Кожухар, О. В. (2015). В А. Б. Аваков (Ред.), Міністерство внутрішніх справ Украйни: події, керівники, документи та матеріали (1917-2017) (Т. 3, 940 с.). Харків: Мачулін.

Стаття надійшла до редакції 15.07.2021

V. Chisnikov, DSc (Law), Associate Professor,

Chief Researcher

Department of Scientific Information and Editorial

and Publishing Activities,

State Research Institute,

MIA of Ukraine, Kiev, Ukraine,

ORCID: https://orcid.org/0000-0003-2020-7298

\section{ELISEEV ALEXANDER AKIMOVICH - ONE OF THE FIRST HEADS OF THE SCIENTIFIC AND TECHNICAL PART OF THE DEPARTMENT OF THE CRIMINAL INVESTIGATION DEPARTMENT OF THE MAIN DIRECTORATE OF POLICE AND INVESTIGATION OF THE UKRAINIAN SSR}

\footnotetext{
The way of life and creative activity of Alexander Akimovich Eliseev (1887-1968), who was one of the pioneers of Soviet forensic science and made a significant contribution to the development of forensic science and forensic examination in Ukraine, is being considered based on little-known Ukrainian militia publications of the 20s of the twentieth century, as well as published works on the history of forensic science. The attention is mainly paid to A. A. Eliseev's activities as the head of the scientific-technical unit (sub-department) of the Criminal Investigation Department of the Main Department of Militia and Tracing of the Ukrainian SSR (1923-1926). Various departmental manuals, instructions, methodological guidelines developed by him during those years, as well as published articles have played an important role in forensic knowledge diffusion among practical employees of Ukraine.

Keywords: Eliseev A. A.; scientific and technical part (subdivision) of the Criminal Investigation Department; registration and fingerprint bureau; Kharkov Office of Scientific and Forensic Expertise of the People's Commissariat of Justice of the Ukrainian SSR; problems of handwriting studies; forensic graphic examination; history of forensic science.
} 
В. М. Чисніков, доктор юридичних наук, доиент, головний науковий співробітник відділу науково-інформаційної та редакиійно-видавничої діяльності, Державний науково-достідний інститут МВС України, м. Київ

ORCID: https://orcid.org/0000-0003-2020-7298

\section{ЄЛИСЄЄВ ОЛЕКСАНДР ЯКИМОВИЧ - ОДИН ІЗ ПЕРШИХ КЕРІВНИКІВ НАУКОВО-ТЕХНІЧНОЇ ЧАСТИНИ ВІДДІЛУ КРИМІНАЛЬНОГО РОЗШУКУ ГОЛОВНОГО УПРАВЛІННЯ МІЛІЦІї ТА РОЗШУКУ УСРР}

На основі маловідомих українських міліцейських видань 20-х рp. ХХ ст., а також опублікованих праць з історії криміналістики розглянуто життєвий шлях і творчу діяльність Олександра Якимовича Єлисєєва (1887-1968) - одного з піонерів радянської криміналістики, який зробив значний внесок у розвиток криміналістичної науки та судової експертизи в Україні. Звернуто увагу переважно на діяльність О. Я. Єлисєєва в період перебування його керівником науково-технічної частини (підвідділу) відділу карного розшуку Головного управління міліції і розшуку УСРР (1923-1926). Розроблені ним в ці роки різні відомчі керівництва, інструкції, методичні вказівки, а також опубліковані статті зіграли важливу роль у поширенні криміналістичних знань серед практичних працівників України.

Ключові слова: Єлисєєв О. Я.; науково-технічна частина (підвідділ) Укрцентророзшуку; реєстраційно-дактилоскопічне бюро; Харківський кабінет науково-судової експертизи НКЮ УСРР; проблеми почеркознавства; судово-графічна експертиза; історія криміналістики. 